\title{
Simulation Research on PEMFC fueled with ammonia reforming gas
}

Jianfeng Zhao ( $\square$ jianfeng62300_zhao@163.com )

Naval University of Engineering

Qianchao LIANG

Naval University of Engineering

Yifan LIANG

Naval University of Engineering

HU Jinyi

Naval University of Engineering

\section{Research Article}

Keywords: Ammonia reforming gas, PEMFC, Local current density, Length optimization, Fuel utilization

Posted Date: October 27th, 2021

DOI: https://doi.org/10.21203/rs.3.rs-1000781/v1

License: (c) (1) This work is licensed under a Creative Commons Attribution 4.0 International License. Read Full License 


\title{
Simulation Research on PEMFC fueled with
}

\author{
ammonia reforming gas \\ ZHAO Jianfeng*, LIANG Qianchao, LIANG Yifan, HU Jinyi \\ (College of Power Engineering, Naval University of Engineering, Wuhan 430033)
}

\begin{abstract}
Ammonia as a chemical storage carrier for hydrogen has the advantages of high hydrogen storage density and easy storage. However, reconversion of ammonia to pure hydrogen requires additional energy consumption and complex equipment, thus greatly reducing its advantages as a hydrogen storage carrier. The development of PEMFC that use ammonia decomposition gas directly as fuel can avoid the purification of hydrogen and simplify on-site hydrogen production systems. Thus, the application of fuel cells can be greatly expanded. In this paper, a three-dimensional simulation model of PEMFC using ammonia reforming gas as fuel is established based on experimental data. The distribution of local current density and local hydrogen concentration inside the fuel cell and the relationship between them are studied and analyzed. The optimal efficiency and fuel utilization of the fuel cell under different flow rates are investigated. Finally, a preliminary simulation analysis of the effect of anode runner length on the maximum output power of the fuel cell is conducted. The results of the study can provide a reference for the fuel control strategy of ammonia reforming gas-fueled PEMFC and the optimization of the fuel cell.
\end{abstract}

Keywords: Ammonia reforming gas, PEMFC, Local current density, Length optimization, Fuel utilization

\section{Introduction}

Proton exchange membrane fuel cells (PEMFC) have gained initial commercial applications in recent years [1]. Currently, PEMFCs are still fueled by high-purity hydrogen, which is expensive to produce and has a low storage volume energy density, so the large-scale application of PEMFC is still limited [2,3]. In contrast, ammonia as a chemical storage carrier for hydrogen has the advantages of high hydrogen storage density and easy storage. However, the product obtained from ammonia reforming is a mixture of nitrogen and hydrogen, which is called crude hydrogen in this paper, so further separation is needed to obtain pure hydrogen. The separation methods for crude hydrogen include deep cooling separation, variable pressure adsorption, and membrane separation [4-6]. For small portable PEMFC on-site hydrogen production units, all of these methods suffer from the problem of large unit size. Therefore, the development of PEMFC using ammonia reforming gas directly is very interesting and can greatly expand the application of PEMFC.

Hunter et al. established an ammonia-reforming gas-PEMFC demonstration platform to demonstrate the feasibility of PEMFC using ammonia reforming gas directly [7]. A large number of studies have been conducted for the efficient decomposition of ammonia, and the hot spots of research are mainly microreactors and efficient catalysts [8,9]. There also have been many studies on the effect of nitrogen on PEMFC, but the studies have mainly targeted the effect of trace amounts of nitrogen. Previous studies have shown that nitrogen affects the diffusion and transport of hydrogen in the flow channel, but when pure hydrogen is used as fuel, its final accumulation is 
not high and is periodically discharged along with the anode purging. Therefore, for a PEMFC using pure hydrogen as fuel, the main purpose of flow channel geometry optimization is to optimize water management, thermal management and material distribution inside the cell [10-12] However, for ammonia reforming gas, experiments show that high concentration of nitrogen significantly affects the operating state of the fuel cell, and due to the high initial concentration of nitrogen, the anode purging strategy cannot guarantee the normal operation of the fuel cell, so only the fuel flow control strategy can be used. Moreover, with the consumption of hydrogen, the concentration of nitrogen in the fuel cell along the flow direction becomes higher and higher, so the operating characteristics of the fuel cell under high concentration of nitrogen must be further studied and analyzed.

In this paper, a three-dimensional simulation model of PEMFC using ammonia reforming gas as fuel is established based on experimental data. The distribution of local current density and local hydrogen concentration inside the fuel cell and the relationship between them are studied and analyzed. The optimal efficiency and fuel utilization of the fuel cell under different flow rates are investigated. Finally, a preliminary simulation analysis of the effect of anode runner length on the maximum output power of the fuel cell is conducted. The results of the study can provide a reference for the fuel control strategy of ammonia reforming gas-fueled PEMFC and the optimization of the fuel cell.

\section{Mathematical modeling}

The experimental data used for modeling in this paper are from a $1 \mathrm{~kW}$ PEMFC experimental system, where the PEMFC is an air-cooled fuel cell (as shown in Figure 1(a)). The anode and cathode channel of the PEMFC are perpendicular to each other, and the flow direction of air and fuel is cross flow. Theoretically, the air composition on the cathode side corresponding to different anode runners will change along the air flow direction (as shown in Fig. 1(b)). However, since PEMFC uses cathode air for cooling, it leads to a much higher air mass flow rate at the cathode than the air mass required for the electrochemical reaction. The minimum air mass flow rate of the PEMFC cathode in the experiment is 77 times the required stoichiometric air mass at rated power, from which it can be estimated that the oxygen concentration at the cathode outlet is only $1.3 \%$ lower than that at the inlet. Therefore, the modeling location in this paper is chosen to be in the mid-profile of the first anode channel at the air inlet , and the air composition at the cathode channel is assumed to be the same as the air $[13,14]$.The model contains seven domains: anode channel, anode gas diffusion layer (an_GDL), anode catalyst layer(an_CL), proton exchange membrane(PEM), cathode catalyst layer(ca_CL), cathode gas diffusion layer(ca_GDL) and cathode channel as shown in Figure 1(c). In order to further simplify the model, the following assumptions are adopted in this paper[15-19]:

(1) Each gas is regarded as an ideal gas.

(2) The generated water can quickly flow out with air in a gaseous form, and there is no liquid water in the cathode.

(3) The temperature distribution in PEMFC is uniform and constant.

(4) The penetration of water and nitrogen from the cathode side to the anode side is ignored. 


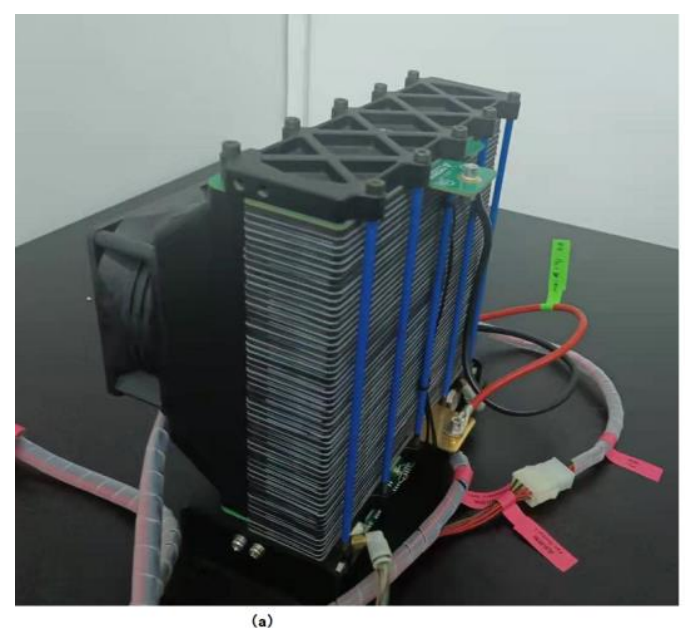

(a)

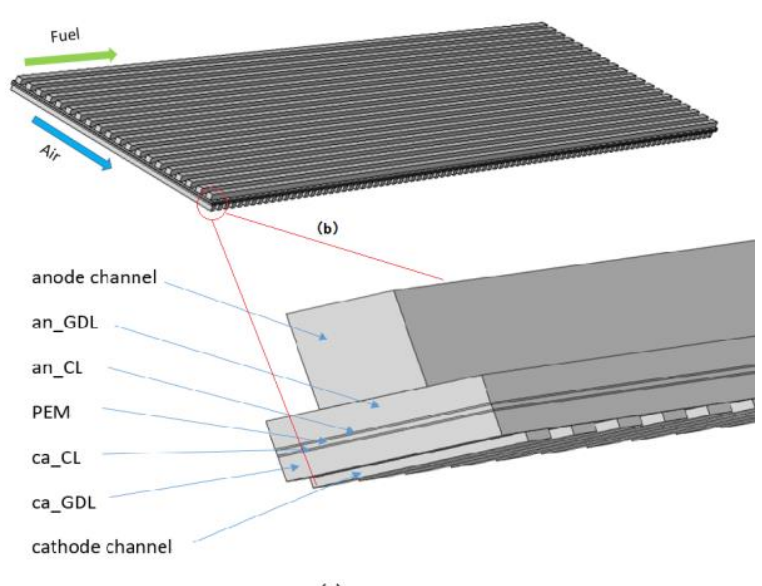

(c)

Fig.1(a)1kW air-cooled PEMFC,(b) Single fuel cell geometry schematic,(c)three-dimensional section of the modeling area

\subsection{Electrochemical model}

The cell voltage $\mathrm{V}$ is described as follows:

$$
V=E_{0}-\eta_{\text {act }}-\eta_{\text {ohm }}
$$

Where $E_{0}$ is the theoretical reversible voltage which can be calculated from the Nernst equation[13]:

$$
E_{0}=1.229-0.85 * 10^{-3} *(T-298.15)+4.3085 * 10^{-5} * T *\left[\ln \left(P_{H_{2}}^{*}\right)+0.5 * \ln \left(P_{\mathrm{O}_{2}}^{*}\right)\right]
$$

Anode local current density $i_{a}$ (Butler-Volmer equation)

$$
i_{a}=i_{0, a} *\left(\frac{c_{H_{2}}}{c_{H_{2, n f}}}\right)^{0.5} *\left(\exp \left(\frac{\alpha_{a, a} F \eta_{a}}{R T}\right)-\exp \left(\frac{-\alpha_{c, a} F \eta_{a}}{R T}\right)\right)
$$

Cathode local current density $i_{c}$ (Butler-Volmer equation)

$$
i_{c}=-i_{0, c}\left(\frac{c_{O_{2}}}{c_{O_{2, r f}}}\right)\left(\exp \left(\frac{\alpha_{c, a} F \eta_{c}}{R T}\right)-\exp \left(\frac{-\alpha_{c, c} F \eta_{c}}{R T}\right)\right)
$$

$F$ is the Faraday's constant (SI unit: $\mathrm{C} \mathrm{mol}^{-1}$ ), $c_{i, \text { ref }}$ is the material reference concentration (SI unit: mol m $\left.\mathrm{m}^{-3}\right), i_{0, a}$ and $i_{0, c}$ is the standard exchange current density (SI unit: $\mathrm{A} \mathrm{m}^{-2}$ ), $R$ is the gas constant, $T$ is the temperature (SI unit: $\mathrm{K}$ ), $\alpha_{a, a}, \alpha_{a, c}, \alpha_{c, a}, \alpha_{c, c}$ is the transfer coefficient.

Anode over-potential $\eta_{a}$, cathode over-potential $\eta_{c}$ and total over-potential $\eta_{a c t}$ are given by the following equation:

$$
\begin{aligned}
& \eta_{a}=\phi_{s}-\phi_{l}-E_{e q, a} \\
& \eta_{c}=\phi_{s}-\phi_{l}-E_{e q, c}
\end{aligned}
$$




$$
\eta_{a c t}=\eta_{a}+\eta_{c}
$$

Where $E_{e q, i}\left(\mathrm{SI}\right.$ unit: V) represents the equilibrium voltage, $\phi_{\mathrm{s}}$ is the electronic potential (IS unit: $\mathrm{V}$ ), and $\phi_{1}$ is the ionic potential (IS unit: V).

Ohmic overpotentia $\eta_{\text {ohm }}$ :

$$
i_{e}=\sigma_{e} * \eta_{\text {ohm }, e}
$$

Where $\sigma_{e}$ (IS unit: $\mathrm{S} \mathrm{m}^{-1}$ ) is the electrical conductivity (where the index $e$ stands for "a"(anode) or "c"(cathode)).

\subsection{Momentum conservation equation}

Navier-Stokes equation and Brinkman equation are adopted to describe the flow in the free zone (anode channel) and porous zone, respectively. [20] The combination of Navier-Stokes equations and continuity equations can be expressed as:

$$
\begin{gathered}
(\rho u \cdot \nabla) u=-\nabla P+\nabla \cdot\left[\mu\left(\nabla u+(\nabla u)^{T}\right)-\frac{2}{3} \mu(\nabla \cdot u) I\right] \\
\nabla \cdot(\rho u)=0
\end{gathered}
$$

Where $\rho$ is the mixture density of the gas phase(SI unit: $\mathrm{kg} \mathrm{m}^{-3}$ ), $I$ is Unit Matrix, $P$ is the pressure(SI unit: $\mathrm{Pa}), \mu$ represents the gas viscosity(SI unit: $\mathrm{Pa}$ s), $\mathrm{u}$ is the velocity.

The combination of Brinkman equation and continuity equation can be expressed as:

$$
\frac{\mu}{k} u=-\nabla p+\nabla \cdot \frac{1}{\varepsilon}\left[\mu\left(\nabla u+(\nabla u)^{T}\right)-\frac{2}{3} \mu(\nabla \cdot u) I\right]
$$

Where $k$ is permeability(IS unit: $\mathrm{m}^{2}$ ), $\varepsilon$ is porosity.

\subsection{Mass conservation equation}

The model takes into account two species in the anode $\left(\mathrm{H}_{2}\right.$ and $\left.\mathrm{N}_{2}\right)$ and three species at the cathode $\left(\mathrm{O}_{2}, \mathrm{H}_{2} \mathrm{O}\right.$ and $\left.\mathrm{N}_{2}\right)$, and uses Maxwell-Stefan multicomponent diffusion, governed by the following equations[20]:

$$
\nabla j_{i}+\rho(u \cdot \nabla) w_{i}=R_{i}
$$

Where $w_{i}$ is mass fraction of species $\mathrm{i}, R_{i}$ is chemical reaction rate of species $\mathrm{i}\left(\mathrm{IS}\right.$ unit: $\mathrm{kg} \mathrm{m}^{-3} \mathrm{~s}^{-1}$ ), $j_{i}$ is the diffusion mass flow density of species $\mathrm{i}$, which is defined as follows: 


$$
\begin{gathered}
j_{i}=-\left(\rho D_{i}^{m} \nabla w_{i}+\rho w_{i} D_{i}^{m} \frac{\nabla M_{n}}{M_{n}}-j_{c, i}\right) \\
D_{i}^{m}=\frac{1-w_{i}}{\sum_{k \neq l} \frac{x_{k}}{D_{i k}}} \\
M_{n}=\left(\sum_{i} \frac{w_{i}}{M_{i}}\right)^{-1} \\
j_{c, i}=\rho w_{i} \sum_{i} \frac{M_{i}}{M_{n}} D_{k}^{m} \nabla x_{k}
\end{gathered}
$$

Here $x_{k}$ is mole fraction, $M_{i}$ is Molecular mass, $\quad D_{i}^{m}$ is the equivalent diffusion coefficient of species i in multicomponent, $D_{i k}$ is binary diffusion coefficient, which can be calculated by Fuller's empirical formula [21]:

$$
D_{i k}=3.198 * 10^{-8} * \frac{T^{1.75}}{P\left(v_{i}^{\frac{1}{3}}+v_{k}^{\frac{1}{3}}\right)^{2}}\left(\frac{1}{M_{i}}+\frac{1}{M_{k}}\right)^{0.5}
$$

Where $v_{i}$ is the molar diffusion volume of gas (IS unit: $\mathrm{cm}^{3} \mathrm{~mol}^{-1}$ ).

The binary diffusion coefficient obtained by Equation (20) needs to be modified in the porous region:

$$
D_{i k_{-} e f f}=\frac{\varepsilon}{\tau} D_{i k}
$$

Here $\tau$ is the tortuosity factor.

\subsection{Initial and boundary conditions of the fuel cell model}

The potential difference between the cathode and anode current collectors corresponds to the total cell voltage. Choose the potential at the upper surface of an_GDL as the reference level by setting it to zero. Then the total cell voltage serves as the boundary condition at the lower surface of ca_GDL:

$$
\begin{aligned}
& \phi_{s}=0 \text { at the upper surface of an_GDL } \\
& \phi_{s}=\mathrm{V} \text { at the lower surface of ca_GDL }
\end{aligned}
$$

The molar fraction of nitrogen at the anode inlet of the fuel cell is 0.25 and the molar fraction of hydrogen is 0.75 . 


\section{Results and Discussion}

\subsection{Verification of simulation model}

Table 1 Geometric parameters, characteristic parameters and boundary conditions of the model

\begin{tabular}{|c|c|c|}
\hline Parameters & Value & Ref. \\
\hline Anode channel length, $L(\mathrm{~mm})$ & 173 & measure data \\
\hline Anode channel height, $H(\mathrm{~mm})$ & 1 & measure data \\
\hline Anode channel width, $W \_$an $(\mathrm{mm})$ & 1 & measure data \\
\hline Width of the rib, $W_{-}$rib(mm) & 1 & measure data \\
\hline Anode channel width, $W \_c a(m m)$ & 1 & measure data \\
\hline Anode gas diffusion layer thickness, $\sigma_{a d}(\mathrm{~mm})$ & 0.29 & [16] \\
\hline Cathode gas diffusion layer thickness, $\sigma_{c d}(\mathrm{~mm})$ & 0.254 & [16] \\
\hline Anode catalyst layer thickness, $\sigma_{a c}(\mathrm{~mm})$ & 0.0165 & [16] \\
\hline Cathode catalyst layer thickness, $\sigma_{c c}(\mathrm{~mm})$ & 0.0165 & [16] \\
\hline PEM thickness, $\sigma_{m}(\mathrm{~mm})$ & 0.0508 & [16] \\
\hline Electrical conductivity, $\sigma_{s}\left(\mathrm{~S} \mathrm{~m}^{-1}\right)$ & 220 & [22] \\
\hline Ionic conductivity, $\sigma_{l}\left(\mathrm{~S} \mathrm{~m}^{-1}\right)$ & 3.5 & $\begin{array}{c}{[22] \text { and }} \\
\text { Optimization }\end{array}$ \\
\hline $\begin{array}{l}\text { Permeability inside an_GDL and ca_GDL domains, } \\
\kappa_{d g l}\left(\mathrm{~m}^{2}\right)\end{array}$ & $1.18 \times 10^{-11}$ & [22] \\
\hline $\begin{array}{l}\text { Permeability inside an_CL and ca_CL domains, } \\
\kappa_{c l}\left(\mathrm{~m}^{2}\right)\end{array}$ & $2.36 \times 10^{-12}$ & {$[22]$} \\
\hline Porosity inside an_GDL and ca_GDL domains, $\varepsilon_{d g l}$ & 0.4 & {$[22]$} \\
\hline Porosity inside an_CL and ca_CL domains, $\varepsilon_{c l}$ & 0.3 & [22] \\
\hline Gas viscosity inside anode domains, $\mu_{a}(\mathrm{~Pa} \mathrm{~s})$ & $1.19 \times 10^{-5}$ & [18] \\
\hline Gas viscosity inside cathode domains, $\mu_{a}(\mathrm{~Pa} \mathrm{~s})$ & $2.46 \times 10^{-5}$ & {$[18]$} \\
\hline Anode standard exchange current density, $i_{0 a}\left(\mathrm{~A} \mathrm{~m}^{-2}\right)$ & $1.5 \times 10^{3}$ & $\begin{array}{c}{[22] \text { and }} \\
\text { Optimization }\end{array}$ \\
\hline $\begin{array}{l}\text { Cathode standard exchange current density, } i_{0 c}(\mathrm{~A} \\
\left.\mathrm{m}^{-2}\right)\end{array}$ & $8 \times 10^{-2}$ & $\begin{array}{c}{[22] \text { and }} \\
\text { Optimization }\end{array}$ \\
\hline Transfer coefficient, $\alpha_{a, a}, \alpha_{a, c}, \alpha_{c, a}, \alpha_{c, c}$ & $0.5,0.5,0.53,0.47$ & $\begin{array}{c}{[16] \text { and }} \\
\text { Optimization }\end{array}$ \\
\hline Tortuosity factor $\tau$ & 1.4 & [22] \\
\hline Cell temperature, $T(\mathrm{~K})$ & 318 & measure data \\
\hline
\end{tabular}

Table 1 shows the parameters used in the model, and Figure 2 shows the comparison between experimental data and simulation results, where curve 1 represents the cathode oxygen concentration is the same as air, and curve 2 represents the cathode oxygen concentration is the same as the cathode outlet oxygen concentration under the minimum air mass flow rate of the fuel cell. Curve 1 and curve 2 in the graph basically overlap, so it is certain that the variation of oxygen concentration under the condition of sufficiently high air excess coefficient has little effect on the simulation results and can be neglected, and the previous assumptions about the simplification of the model geometry region in this paper are reasonable. At the same time, the experimental data 
and the simulation data can be in good agreement, so it can be considered that the model is applicable in this paper.

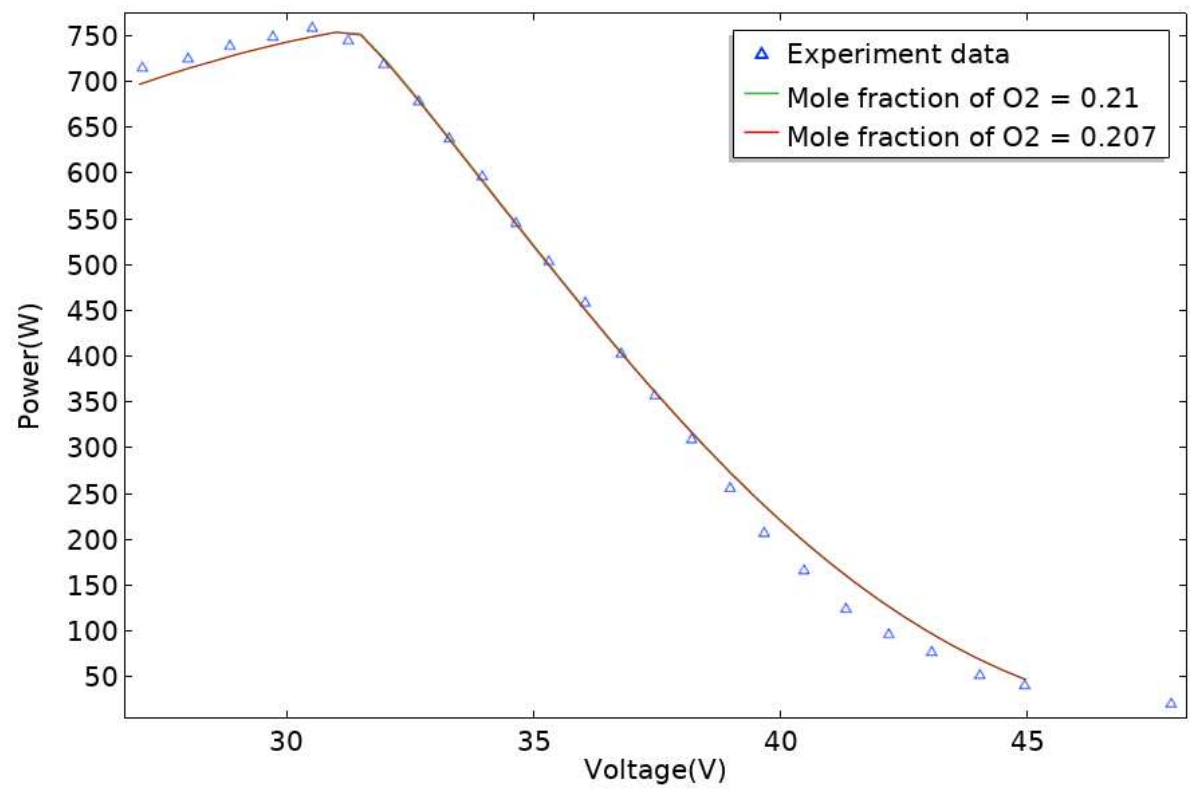

Figure2. Comparison of simulation results and experiment

\subsection{Local current density distribution of the PEM at different output voltages}

Comparing the local current density distribution at different voltages in Fig. 3, the local current density increases with decreasing output voltage at the anode inlet, but the opposite is true at the anode outlet. When the output voltage is too low, for example, $\mathrm{V}=0.54$ in the figure, the local current density at the anode outlet drops sharply to zero, and the area with zero local current density near the anode outlet gradually expands as the output voltage decreases. The reason for zero local current density when the output voltage is low is that the hydrogen concentration is close to zero due to high consumption of hydrogen in the fuel. Low local current density can lead to local over-potential in the proton exchange membrane, which in turn can lead to deterioration of the proton exchange membrane performance and therefore needs to be avoided.In Figure 3 it can also be seen that there are regular waves in the local current distribution surface, and the reason for this phenomenon is that the cathode runners and ribs lead to periodic changes in the cathode oxygen concentration as shown in Figure 4. At the same time, there is a significant decrease at the anode entrance, which is also due to the fact that the entrance corresponds exactly to the rib and wall, where the oxygen concentration is much lower. 


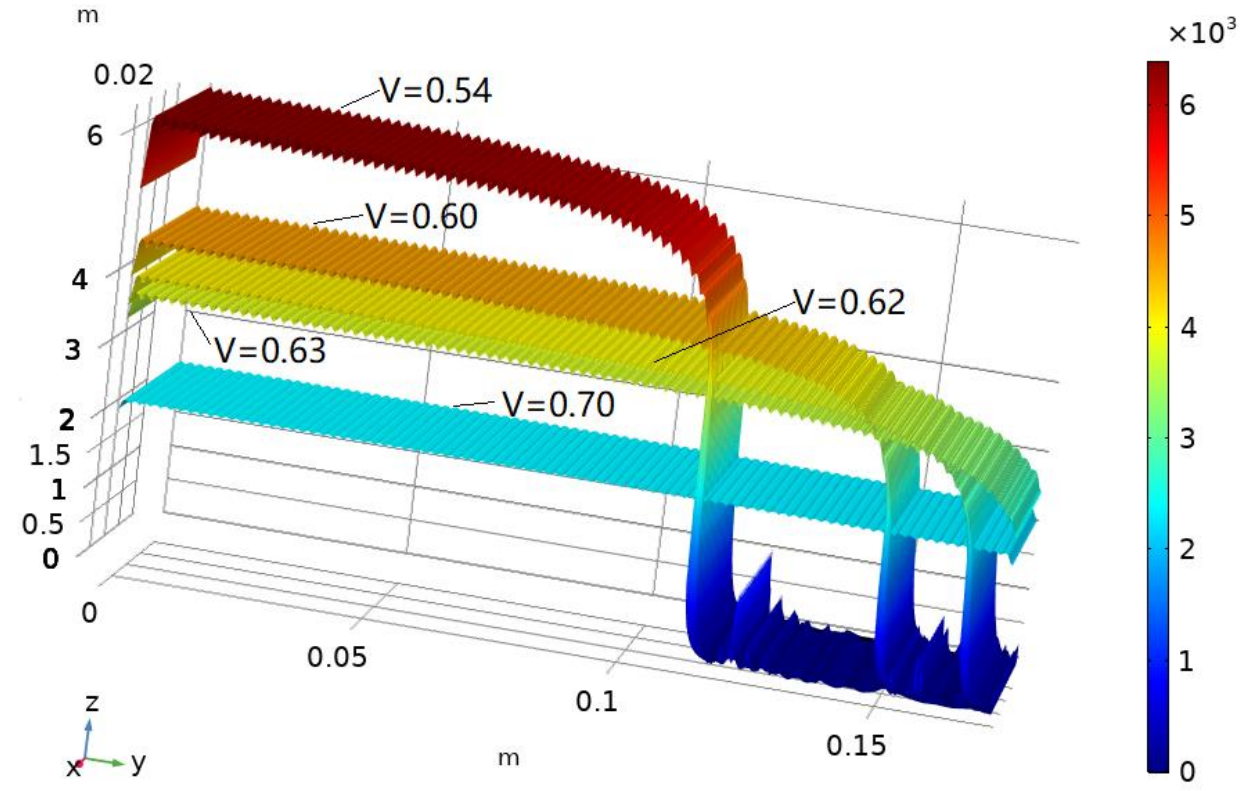

Figure 3. Local current density at different output voltages ( $x$-axis represents cathode direction, $y$-axis represents anode direction)

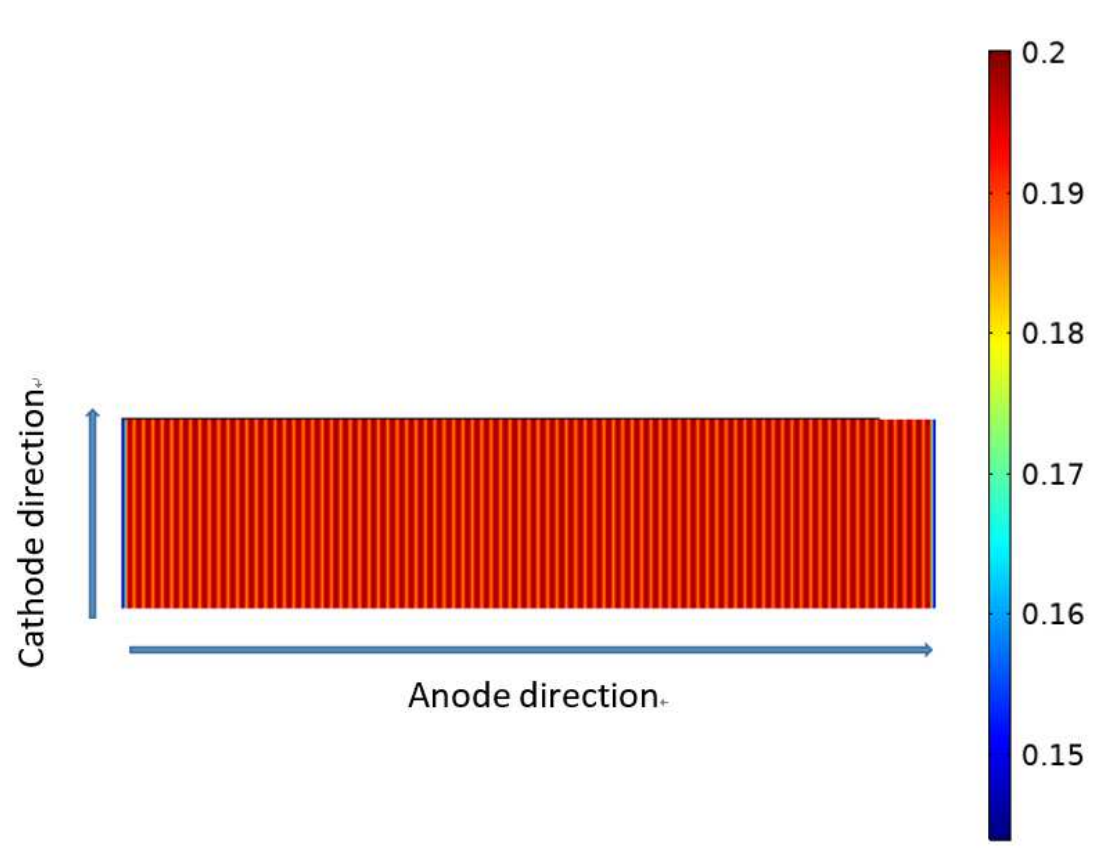

Figure 4. Local oxygen concentration distribution in the cathode catalyst layer

\subsection{Distribution of hydrogen concentration at different output voltages}

Figure 5 shows the local concentration distribution of hydrogen in the anode catalyst layer at different output voltages. In the figure when $\mathrm{V}=0.54$, the molar concentration of hydrogen is close to 0 in the region near the anode exit, for which also corresponds to the distribution of zero local current density in section 3.2. The hydrogen concentration distribution is in a clear variation along the anode runner until it drops to zero. However, the local current density distribution in Fig. 4 shows an approximately uniform local current density distribution near the anode inlet, which indicates that at higher hydrogen concentrations, the change in hydrogen concentration has little 
effect on the local current density, and the threshold value of the molar concentration is about 0.03 based on the simulation data. Also a regular wave distribution appears in the direction along the cathode channel, which is caused by the influence of the anode ribs.

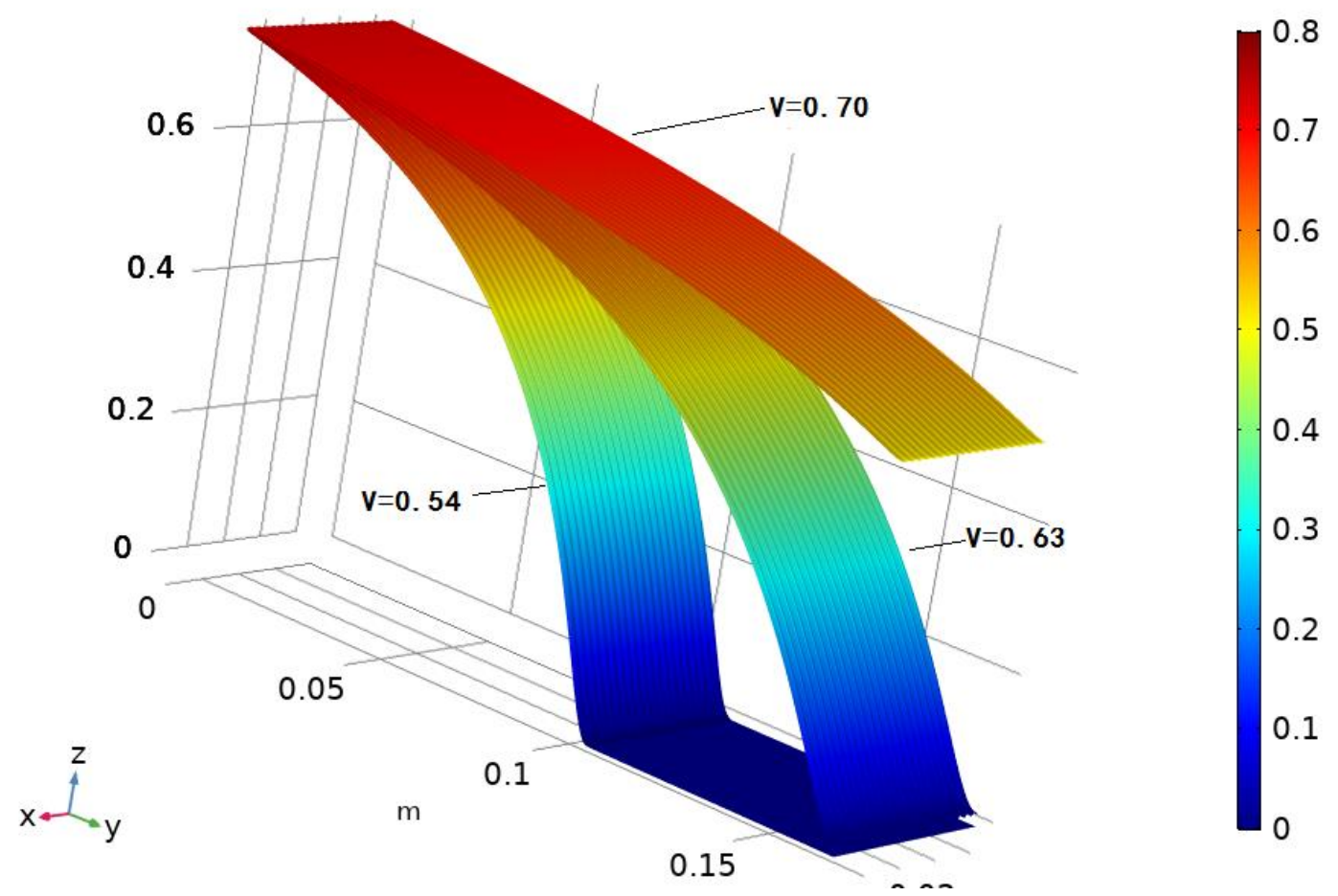

Figure 5. The local concentration distribution of hydrogen in the anode catalyst layer at different output voltages

Figure. 6a shows the 3-dimensional distribution of the local molar concentration of hydrogen when the output voltage $\mathrm{V}=0.60$, in which the molar concentration of hydrogen is significantly lower towards the end of the anode channel compared to the inlet. Figure $6 \mathrm{~b}$ shows the local hydrogen molar distribution in cross-section at different locations along the anode direction, and the figure shows a uniform concentration distribution. The above phenomena show that of the two effects of nitrogen on hydrogen, the hydrogen concentration effect and the diffusion effect, the former has a heavier effect on the output characteristics of the fuel cell.

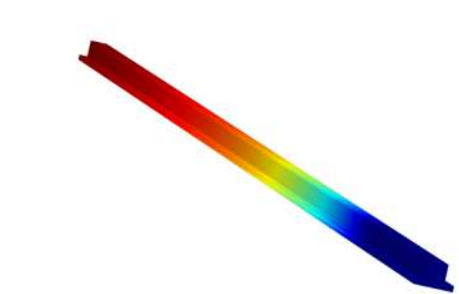

$y_{z}^{y-x}$

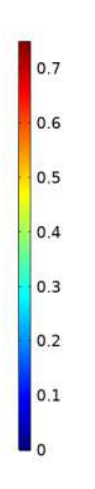

(a)

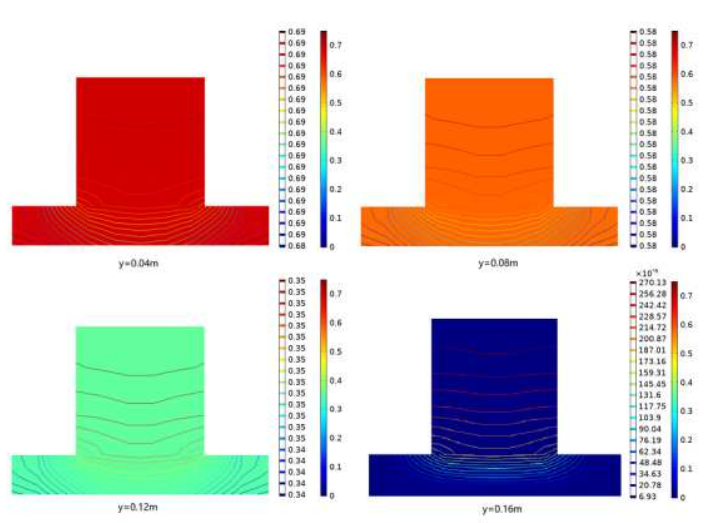

(b)

Figure 6. (a) 3-dimensional distribution of local molar concentration of hydrogen, (b) distribution of molar concentration of hydrogen in cross-section at different positions along the anode 
direction

3.4 Output voltage and fuel utilization corresponding to the maximum efficiency of the fuel cell at different fuel flow rates

Figure 7 shows the maximum efficiency of the fuel cell at different fuel flow rates, as well as the output voltage and fuel utilization corresponding to the maximum efficiency. It can be seen from the figure that as the fuel flow rate decreases, the efficiency of the fuel cell increases and the fuel utilization remains basically the same, witch ranges from 0.891 to 0.889 , while the output voltage gradually increases.

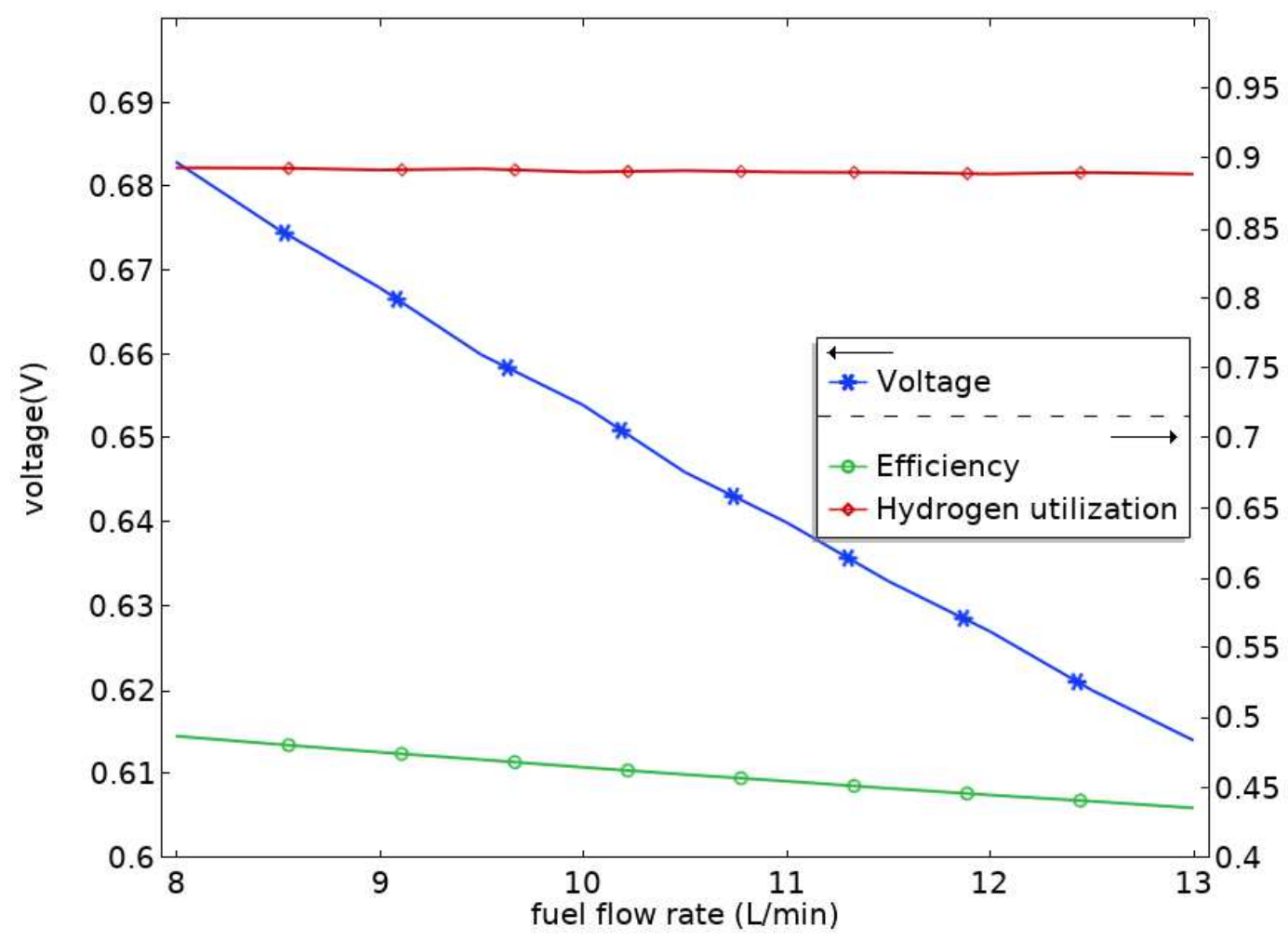

Figure 7 The maximum efficiency of the fuel cell at different fuel flow rates, as well as the output voltage and fuel utilization corresponding to the maximum efficiency.

\subsection{Effect of anode length on fuel cell's max output power}

Figure 8 shows the maximum power and corresponding voltage variation curve of the fuel cell with different anode lengths with the same plate area at a fuel flow rate of $12 \mathrm{~L} / \mathrm{min}$. It can be seen from the figure that the maximum output power increases as the anode length decreases., and the variation is basically linear. For every $10 \mathrm{~mm}$ reduction in anode length, the maximum output power of the fuel cell is increased by $7.75 \mathrm{~W}$. 


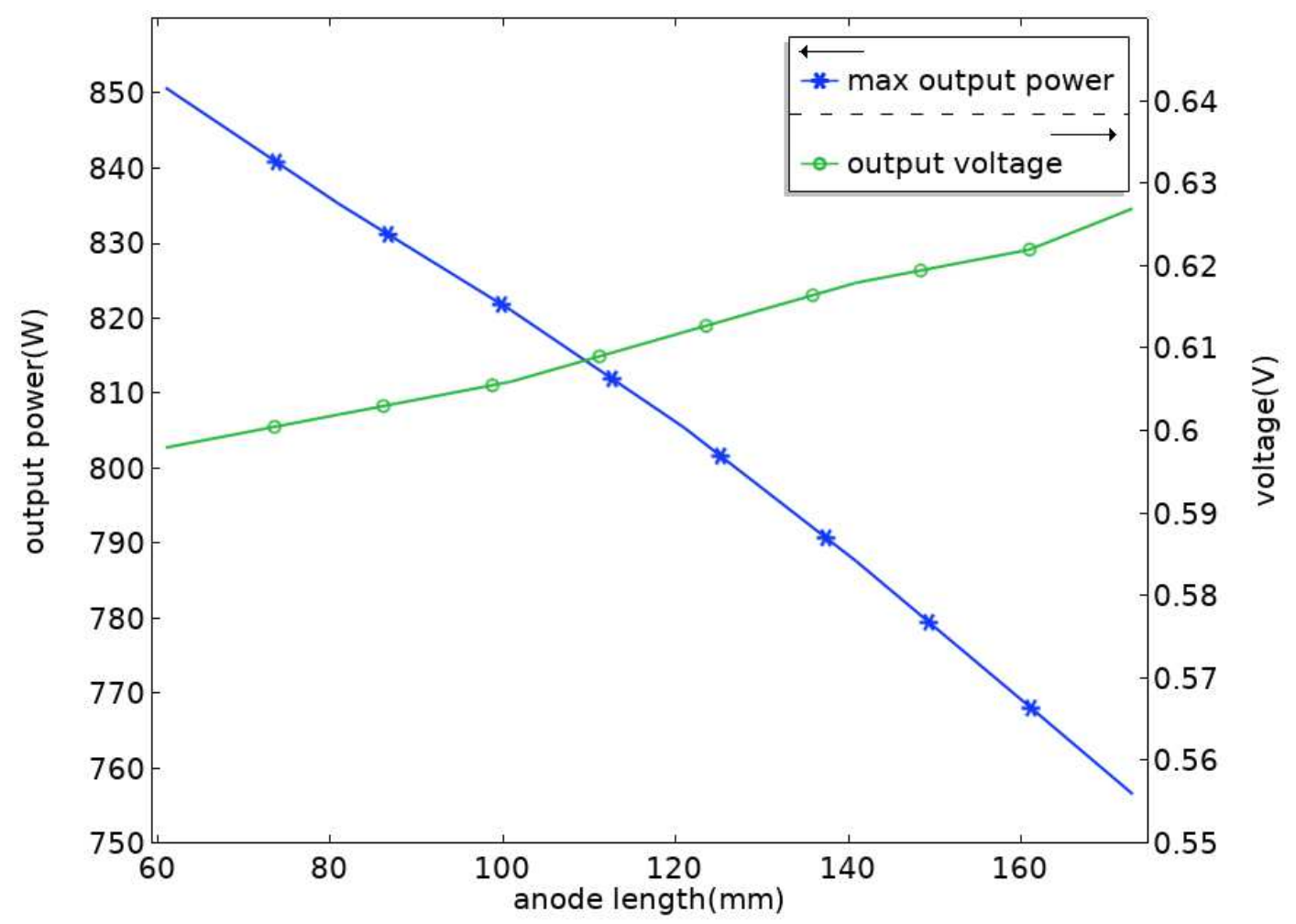

Figure 8 The maximum power and corresponding voltage variation curve of the fuel cell with different anode lengths

\section{Conclusion}

In this paper, a three-dimensional simulation model of PEMFC fueled by ammonia reforming gas is established, and the simulation model is modified by experimental data. The distribution of local current density and local hydrogen concentration at different output voltages are studied and analyzed, and the threshold value of local molar concentration of hydrogen affecting local current density is 0.03 . The trend of optimal efficiency of fuel cell at different flow rates is studied and the utilization rate of fuel at optimal efficiency is about 0.89. Finally, a preliminary simulation analysis of the effect of anode runner length on the maximum output power of fuel cell was conducted, and it was found that the maximum output power of fuel cell can be increased by reducing the anode runner length with the same plate area. For every $10 \mathrm{~mm}$ reduction in anode length, the maximum output power of the fuel cell is increased by $7.75 \mathrm{~W}$. The study results show that the PEMFC fueled by ammonia reforming gas can achieve well output characteristics with reasonable flow control strategy and structural optimization, which indicates its potential for further research and development.

\section{References:}

[1] Zachary P. Cano, Dustin Banham, Siyu Ye, et al. Batteries and fuel cells for emerging electric vehicle markets. [J].Nature Energy,2018, 3(4):279-289.

[2] Khzouz M , Gkanas E I , Shao J , et al. Life Cycle Costing Analysis: Tools and Applications for Determining Hydrogen Production Cost for Fuel Cell Vehicle Technology[J]. Energies, 2020, 13(15):3783.

[3] Moradi R , Groth K M . Hydrogen storage and delivery: Review of the state of the art technologies and risk and 
reliability analysis[J]. International Journal of Hydrogen Energy, 2019, 44(23):12254-12269.

[4] Sajjan P , Nayak V , Padaki M, et al. Fabrication of Cellulose acetate film by blending technique with palladium acetate for Hydrogen gas separation[J]. Energy \& Fuels, 2020,34, 11699-11707.

[5] Abubakar Alkali. Electroless Plating of Palladium Membranes on Porous Substrates for Hydrogen Separation and the Effects of Process Factors on Plating Rate and Efficiency: A Review[J]. Journal of Power and Energy Engineering ,2020, 08(02):1-19.

[6] Kamakshi, Rajesh Kumar, Vibhav K. Saraswat, et al. Active block copolymer layer on carboxyl-functionalized PET film for hydrogen separation[J]. International Journal of Hydrogen Energy,2020, 45(37):18676-18684.

[7] Hunter H , Makepeace J W ， Wood T J , et al. Demonstrating hydrogen production from ammonia using lithium imide - Powering a small proton exchange membrane fuel cell[J]. Journal of Power Sources, 2016, 329:138-147.

[8] JUSSI IKÄHEIMO, JUHA KIVILUOMA, ROBERT WEISS, et al. Power-to-ammonia in future North European $100 \%$ renewable power and heat system. Int. J. Hydrog. Energy, 2018, 43(36):17295-17308.

[9] Badescu V . Optimal design and operation of ammonia decomposition reactors[J]. International Journal of Energy Research, 2020,44: 5360-5384.

[10] Aiyejina A ， Sastry M . PEMFC Flow Channel Geometry Optimization: A Review[J]. Journal of Fuel Cell Science \& Technology, 2012, 9(1):011011.

[11] Yang C, Wan Z, X Chen, et al. Geometry optimization of a novel M-like flow field in a proton exchange membrane fuel cell[J]. Energy Conversion and Management, 2020, 228(9):113651.

[12] Chen W H , Tsai Z L , Chang M H , et al. Geometry optimization and pressure analysis of a proton exchange membrane fuel cell stack[J]. International Journal of Hydrogen Energy, 2021(1).

[13] Grigoriev S A, Kalinnikov A A, Kuleshov N V , et al. Numerical optimization of bipolar plates and gas diffusion electrodes for PBI-based PEM fuel cells[J]. International Journal of Hydrogen Energy, 2013, 38(20):8557-8567.

[14] Liu, Chen, Xie. A two-dimensional analytical model of PEMFC with dead-ended anode[J]. International Journal of Green Energy, 2020, 17(4):255-273.

[15] Nima Ahmadi, Abdolrahman Dadvand, Iraj Mirzaei, et al. Modeling of Polymer Electrolyte Membrane Fuel Cell with circular and elliptical cross-section gas channels: A novel procedure[J]. International Journal of Energy Research, 2018, 42(8):2805-2822.

[16] Jia Xing Liu, Hang Guo, Fang Ye, et al. Two-dimensional analytical model of a proton exchange membrane fuel cell[J]. Energy, 2017, 119:299-308.

[17] Tsai S W , Chen Y S . A mathematical model to study the energy efficiency of a proton exchange membrane fuel cell with a dead-ended anode[J]. Applied Energy, 2017, 188:151-159.

[18] Wang B , Wu K, Yang Z, et al. A quasi-2D transient model of proton exchange membrane fuel cell with anode recirculation[J]. Energy Conversion \& Management, 2018, 171(PT.1083-186):1463-1475.

[19] Yesilyurt S , Siegel J B , Stefanopoulou A G . Modeling and Experiments of Voltage Transients of Polymer Electrolyte Membrane Fuel Cells With the Dead-Ended Anode[J]. Journal of Fuel Cell ence \& Technology, 2012, 9(2):021012.

[20] Le Bars M , Worster M G . Interfacial conditions between a pure fluid and a porous medium: implications for binary alloy solidification[J]. Journal of Fluid Mechanics, 2006, 550(-1):149-173.

[21] Kee R J , Coltrin M E , Glarborg P , et al. Chemically Reacting Flow: Theory, Modeling, and Simulation[M]. Wiley ,2017:91-149.

[22] Ubong E U , Shi Z , Wang X. Three-Dimensional Modeling and Experimental Study of a High Temperature PBI-Based PEM Fuel Cell[J]. Journal of the Electrochemical Society, 2009, 156(10):B1276-B1282. 